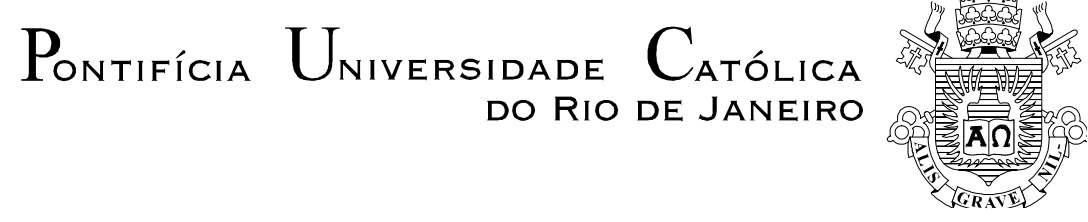

Fábio Flores

\title{
A CONVERSÃO ADJETIVO/SUBSTANTIVO EM FORMAÇÕES DEVERBAIS X-DO NO PORTUGUÊS DO BRASIL
}

\section{Dissertação de Mestrado}

Dissertação apresentada ao Programa de Pósgraduação em Estudos da Linguagem do Departamento de Letras da PUC-Rio como parte dos requisitos parciais para obtenção do título de Mestre em Letras/Estudos da Linguagem.

Orientador: Prof. Margarida Maria de Paula Basilio 


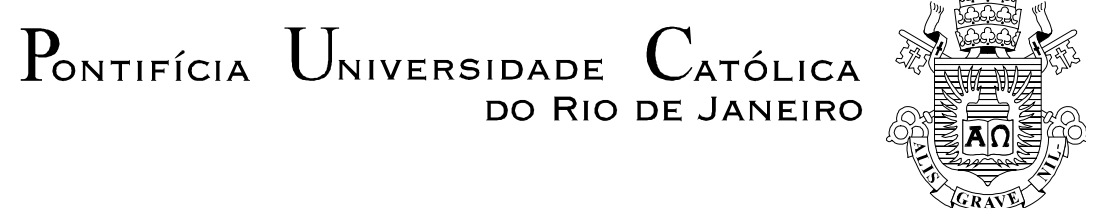

FÁBIO FLORES

\section{A CONVERSÃO ADJETIVO/SUBSTANTIVO EM FORMAÇÕES DEVERBAIS X-DO NO PORTUGUÊS DO BRASIL}

Dissertação apresentada como requisito parcial para obtenção do grau de Mestre pelo Programa de Pós-Graduação em Estudos da Linguagem do Departamento de Letras do Centro de Teologia e Ciências Humanas da PUC-Rio. Aprovada pela Comissão Examinadora abaixo assinada.

Profa. Margarida Maria de Paula Basilio

Orientadora

Departamento de Letras - PUC-Rio

Profa. Erica dos Santos Rodrigues

Departamento de Letras - PUC-Rio

Prof. Carlos Alexandre Victorio Gonçalves

UFRJ

Profa. Denise Berruezo Portinari

Coordenadora Setorial do Centro de Teologia

e Ciências Humanas - PUC-Rio

Rio de Janeiro, 01 de abril de 2013. 
Todos os direitos reservados. É proibida a reprodução total ou parcial do trabalho sem autorização da universidade, do autor e do orientador.

\section{Fábio Flores}

Graduou-se em Letras (Português/Inglês) na UVA (Universidade Veiga de Almeida) em 2004. Especializou-se em Língua Inglesa na UVA em 2006 e em Língua Portuguesa no Liceu Literário Português em 2007. É professor de Língua Inglesa da rede municipal do Rio de Janeiro.

Ficha Catalográfica

Flores, Fábio

A conversão adjetivo/substantivo em formações deverbais X-do português do Brasil / Fábio Flores ; orientador: Margarida Maria de Paula Basílio. - 2013. $92 \mathrm{f}$; $; 30 \mathrm{~cm}$

Dissertação (mestrado)-Pontifícia Universidade Católica do Rio de Janeiro, Departamento de Letras, 2013.

Inclui bibliografia.

1. Letras - Teses. 2. Morfologia. 3. Léxico. 4. Metonímia. 5. Conversão. 6. Língua portuguesa. 7. Substantivo. 8. Adjetivo. 9. Particípio passado. I. Basílio, Margarida Maria de Paula. II. Pontifícia Universidade Católica do Rio de Janeiro. Departamento de Letras. III. Título. 
Para meus pais, Sérgio e Margarete, pelo apoio e pela confiança em todos os momentos. 


\section{Agradecimentos}

À minha orientadora, professora Margarida Basilio. Ser orientaDO por ela é uma experiência fascinante.

À PUC-Rio, pelos auxílios concedidos, sem os quais este trabalho não poderia ter sido realizado.

A todos os professores que tive durante o curso.

Aos professores que fizeram parte da comissão examinadora: Carlos Alexandre Gonçalves e Érica dos Santos Rodrigues.

Aos meus amigos da PUC-Rio: Carlos Roberto de Souza Rodrigues e Igor de Oliveira Costa.

Às minhas amigas da Escola Municipal Estácio de Sá: Cynthia Muniz e Mônica Pinto. 


\section{Resumo}

Flores, Fábio; Basilio, Margarida Maria de Paula. A conversão Adjetivo/Substantivo em formações deverbais X-do no Português do Brasil. Rio de Janeiro, 2013. 92p. Dissertação de Mestrado Departamento de Letras, Pontifícia Universidade Católica do Rio de Janeiro.

Este trabalho investiga as formações deverbais X-do, com o objetivo de determinar até que ponto tais formações estariam circunscritas à classe dos adjetivos ou, ao contrário, apresentariam propriedades também de substantivos. Inicialmente discorre-se sobre o problema da classificação de palavras segundo diferentes perspectivas, tais como as da gramática tradicional e a do Estruturalismo. A seguir, trata-se da questão da conversão categorial e do tratamento dado pela gramática tradicional (como derivação imprópria) e pela Morfologia Lexicalista com respeito às categorias lexicais. Ademais, trata-se da questão da relação entre o adjetivo em -do e a função gramatical do particípio passado. Também se aborda o papel da metonímia ao lado do processo morfológico de formação de nomes de afetado do tipo X-do. Finalmente, discorrese acerca de casos específicos, coletados a partir do jornal "O Globo" durante dois meses. O apêndice constitui-se de testes elaborados a fim de identificar quais formações ocorrem como substantivos convertidos, quais ocorrem como substantivos apenas em contextos restritos a ocorrências genéricas e quais ocorrem apenas como adjetivos. As conclusões são apresentadas a partir dos resultados verificados mediante a aplicação dos testes.

\section{Palavras-chave}

Morfologia; léxico; metonímia; conversão; língua portuguesa; substantivo; adjetivo; particípio passado. 


\section{Abstract}

Flores, Fábio; Basilio, Margarida Maria de Paula (Advisor). The Adjetive/Noun conversion in $\mathrm{X}$-do type deverbal constructions in Brazilian Portuguese. Rio de Janeiro, 2013. 92p. MSc. Dissertation. Departamento de Letras, Pontifícia Universidade Católica do Rio de Janeiro.

This work investigates $\mathrm{X}$-do type deverbal constructions, in order to determine whether such constructions are restricted to the class of adjectives or, on the contrary, they would also present properties that are also typical of nouns. Firstly, we consider the problem regarding word classes according to different perspectives, such as Traditional Grammar and Structuralism. Then, we discuss categorial conversion and its treatment in Traditional Grammar and Lexicalist Morphology. Also, we discuss the relation between the X-do type adjective and the past participle grammatical function. We approach the role of metonymy as well, in connection with $\mathrm{X}$-do formations corresponding to patient or affected roles. Finally, we analyze specific cases, collected from "O Globo" newspaper for the period of two months. The appendix consists of tests elaborated in order to identify which formations occur as nouns formed by conversion and which occur only as adjectives. Conclusions are presented according to the results obtained through the application of the tests.

\section{Keywords}

Morphology; lexicon; metonymy; conversion; Portuguese language; nouns; adjectives; past participle. 


\section{Sumário}

1.Introdução

10

2. A classificação de adjetivos e substantivos ..................................................................... 13

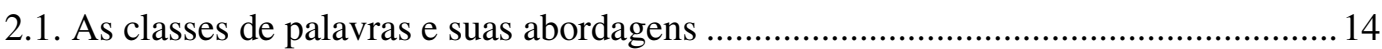

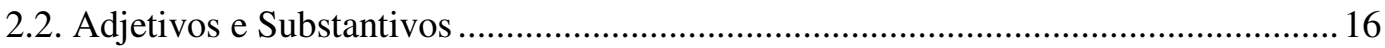

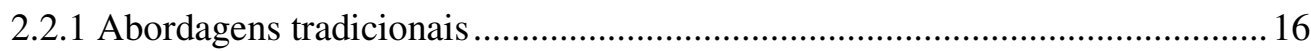

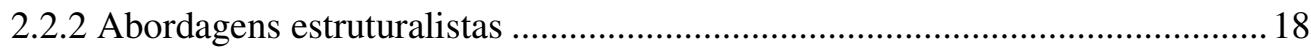

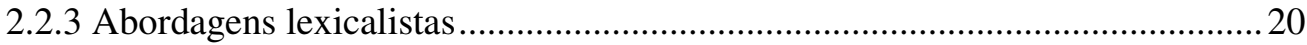

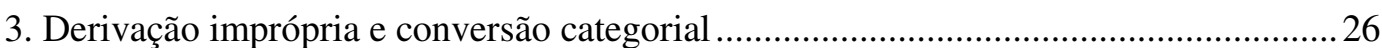

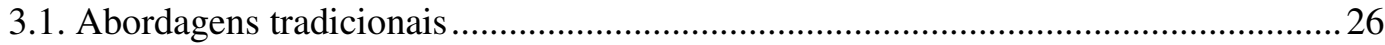

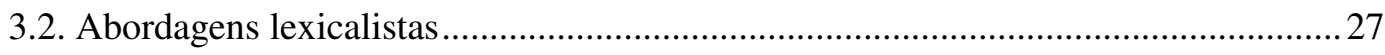

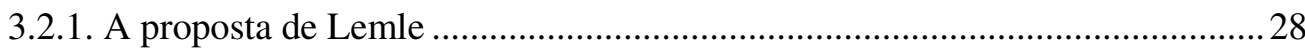

3.2.2. A proposta de Basilio: Substantivação plena e substantivação precária ..........29

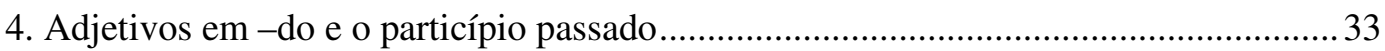

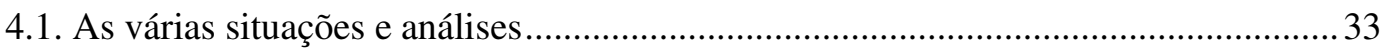

4.2. Formações em X-do: Substantivação plena e precária................................................... 38

4.2.1. Substantivos formados por conversão a partir de adjetivos X-do derivados de

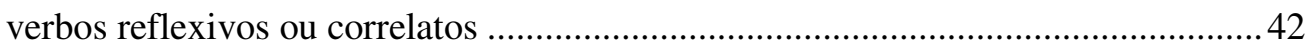

4.2.2. Substantivos formados por conversão a partir dos demais adjetivos X-do ..... 43

5. Substantivos X-do: Análise do corpus coletado

6. O papel da metonímia nos substantivos X-do 
7. Conclusões, dúvidas e problemas..

8. Referências bibliográficas .

73

9. Apêndice: Testes de identificação de substantivos 76 